\title{
Transport infrastructure safety improvement based on digital technology implementation
}

\author{
Aleksey Marusin \\ Transport Maintenance Department, \\ Saint Petersburg State University of \\ Architecture and Civil Engineering \\ Saint Petersburg, Russia \\ Vehicle Parts and Theory of Mechanisms \\ Department \\ Moscow Automobile and Road Construction \\ State Technical University (MADI) \\ Moscow, Russia \\ 89312555919@mail.ru*
}

\author{
Alexandr Marusin \\ Department of Mechanical Engineering \\ and Instrument Engineering \\ RUDN University \\ Moscow, Russia \\ 89271333424@mail.ru
}

\author{
Timur Ablyazov \\ Department of Construction Economics and \\ Housing and Utility Infrastructure \\ Saint Petersburg State University of \\ Architecture and Civil Engineering \\ Saint Petersburg, Russia \\ 3234969@mail.ru
}

\begin{abstract}
The digital technology implementation in the transport infrastructure safety practice promotes reducing accident rates on Russian roads, however, the nationwide tasks of achieving "vision zero" have not been achieved yet. One of the tasks of improving the transport infrastructure safety is the implementation of systems for automatic traffic offence recording as the basis for a digital model in the field of transport infrastructure. For many years, Russia has been improving the state and business interaction mechanisms, developing the conditions for investments attraction in socially significant and large-scale projects, and as a result, the transport infrastructure development relates to the spread of the practice of applying the public private partnership mechanism. The paper covers the issues regarding the traffic safety using a digital model based on systems for automatic traffic offence recording and the public private partnership based mechanism is proposed as an economic tool for transport infrastructure digitization to provide for interaction between the entities of automatic traffic offence recording systems implementation and operation. In our opinion, the interaction of entities involved in the traffic safety process using the automatic traffic offence recording systems based on the public private partnership mechanism opens the potential for development of digital technologies in this subject domain and promotes the innovative development of transport infrastructure under conditions of the digital economy formation.
\end{abstract}

Keywords-automatic recording system, public private partnership, administrative offenses, digital technologies, traffic safety improvement, efficiency.

\section{INTRODUCTION}

A key trend of development of the Russian transport infrastructure is traffic safety (TS) improvement. To solve this problem the measures within the framework of the Federal Target Programs (FTP) for "Traffic Safety Improvement" have been taken since 2006. A key factor in ensuring the traffic safety in accordance with the Federal Law No. 196 "On Road Traffic Safety" dated November 15, 1995 is "activity for preventing the causes of traffic accidents", which is also reflected in the concept of "vision zero on roads" [1].

One of the elements to improve the transport infrastructure safety is the implementation of a digital model based on automatic recording system (ARS) of road traffic offense (RTO), which also requires the effective mechanisms of interaction between entities that ensure roads control and safety. The ARS digital model is already operational in practice, however, improving the transport infrastructure safety requires solving many scientific and technical problems that can improve road safety with the use of automatic recording systems, which can be achieved on the basis of such an economic tool as public private partnership (PPP).

The global experience in PPP application in the fields of construction and housing and utilities infrastructure has shown its high efficiency compared to conventional contract forms. The PPP mechanism application is one of the most common ways to finance the construction of infrastructure facilities for various purposes including education, health, treatment facilities, but the most PPP widespread has been in the framework of transport infrastructure improvement. Globally, for a period of 1986-2011 more than 1300 PPP projects in the transport sector were implemented for aggregate investments of US\$ 350 billion. [2].

Such infrastructure projects as the "Western High Speed Diameter" in Saint Petersburg; "Development of the Vostochny-Nakhodka Transport Hub; "Integrated Development of the Murmansk Transport Hub"; "Integrated Development of the Novorossiysk Transport Hub", etc. have been implemented in Russia based on the PPP mechanisms. Thus, in the current difficult economic situation, the public private partnership is one of the most important economic tools for digital transformation of the transport infrastructure.

\section{BACKGROUND PAPER}

The road safety issues are one of the main trends in modern urban environment formation since a gradual transition to the "smart city" technologies implies increasing the safety level of transport infrastructure facilities functioning [3]; change to electric cars and unmanned vehicles is a long-term prospects in the framework of digital economies, while the traffic safety shall be implemented now. Currently, there are 4 groups of measures to improve the traffic safety [4]:

*corresponding author

The article was prepared as part of the work on the grant of the President of the Russian Federation NSh-4028.2018.6 
1) Improving the operational properties of road infrastructure facilities, for example, increasing a number of lanes, repairing the roadway, etc.

2) Improving the traffic management processes aimed not only at the installation of the physical elements of traffic control (signs, markings, fences), but also at the implementation of technical means such as the systems for automatic traffic offense recording.

3) Manufacturers' improvement in vehicle design performance.

4) Increase in the awareness of drivers about the road safety carried out by public organizations, as well as within the framework of drivers training.

Activities to ensure road safety are considered in the class of organizational systems - multifunctional, hierarchical, with many factors affecting the efficiency, and functionally binding types of implemented activities connected by the unity of system-wide goals [5]. The system for automatic traffic offense recording is a set of technical means (functional elements of the system) that interact with each other to achieve a common goal [1]. Thus, the ARS acts as a digital model including various digital technologies in the field of transport infrastructure.

A number of detected traffic offenses is constantly growing in Russia - this is provided by expanding the functionality of the packages of the automatic recording system and increasing a number of control stations. Over a period of 10 years, a traffic offense mostly detected in the automatic mode remains the same - failure to comply with the speed limit (Fig. 1), it accounts for $74 \%$ of all identified offenses.

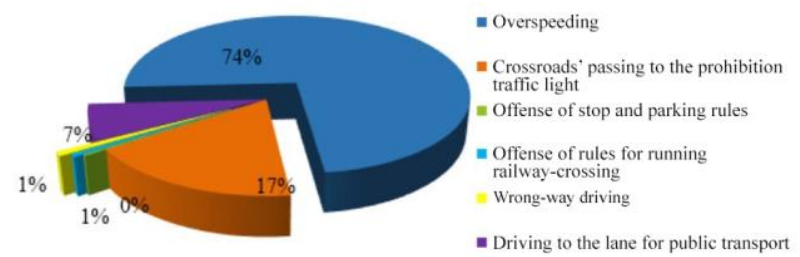

Fig. 1. The offenses mostly identified with the help of offense ARS in Russia.

However, the further spread of digital technologies within the framework of the digital model based on ARS under conditions of a budget deficit requires the development of a mechanism for effective interaction between the public and the private sector that can be PPP.

The Federal Target Program "Traffic Safety Improvement in 2013-2020" and the order of the Government of the Russian Federation No. 1-p dated 08.01.2018 present the measures aimed at solving the traffic safety problem $[6,7]$. As part of implementing the measures of the federal target program to improve traffic safety in 2006-2012 and 2013-2020 a decrease in traffic accidents in Russia was recorded $[6,8]$. Moreover, the increase in control station within the sections of the road network (RNW) has provided greater efficiency in identifying offenses and receiving the funds from fines collection (Fig. 2).

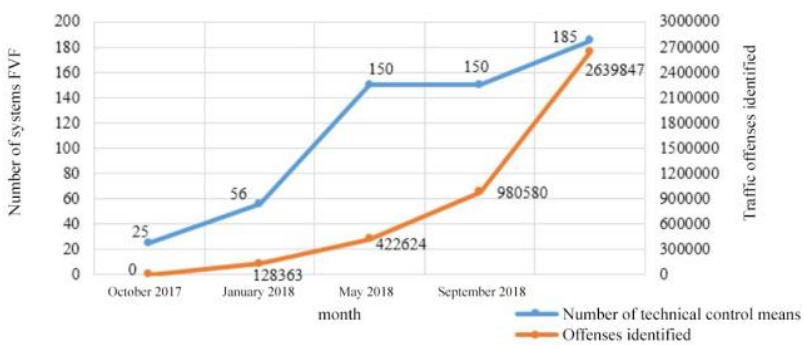

Fig. 2. Change in a number of packages (control stations) and the amount from the fines collection.

Thus, the analysis presented in Fig. 2 suggests the need for further attraction of investments to provide more efficient equipping the regions with tools of automatic recording of administrative offenses, as well as their operation, which can be done only due to mutually beneficial conditions for the state and business. In our opinion, one of the main ways of implementing the projects for development of digital tools to improve the transport infrastructure safety is the PPP mechanism which is used in various fields in the global practice, but it has not received widespread distribution in Russia in the field of improving the technical equipment of roads, in particular, the implementation and operation of such digital model element as the automatic recording system at the objects of transport infrastructure.

The PPP mechanism is a form of multi-level interaction between various government bodies and the private sector, including design and construction organizations, as well as financial institutions and insurance companies [2]. Within the framework of PPP, it is possible to establish productive relations between public and private partners when implementing the infrastructure project which leads to an optimal ratio of the cost of facilities construction and operation and the quality level of services provided. Moreover, the PPP projects often have an innovative focus, since the PPP mechanism allows to effectively distribute risks among the project participants, which is especially important for high-risk projects that have no analogues.

\section{MATERIAL AND METHODS}

Throughout the entire period of using the ARS digital model, a number of detected traffic offenses has been steadily increasing which increases the amount of decrees issued (Fig. 3), and, accordingly, fines collected. The implementation of these digital technologies has allowed to effectively detecting traffic offenses, however, further ARS distribution is necessary, which requires mutually beneficial cooperation between the state and the private sector based on the PPP mechanism.

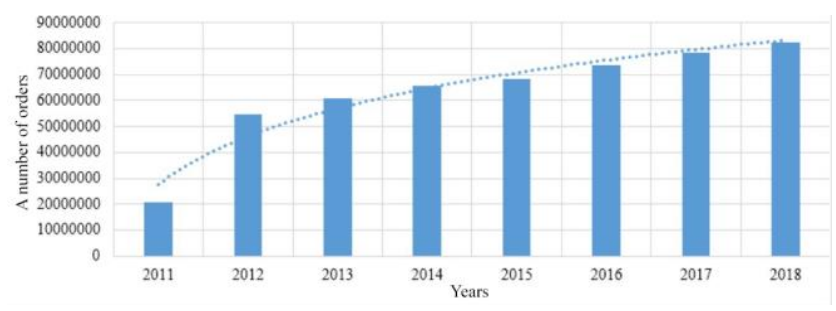

Fig. 3. The sum of the issued decrees when applying the ARS for 20112018. 
The study establishes the relationship between accident indicators and the ARS functioning, while ensuring the traffic safety. The indicators characterizing the effectiveness of the system functioning will be [9-12]: a specific number of fines per day per 1 million registered vehicles - Vehicle Fspec and a specific number of accidents caused by drivers per day per 1 million registered vehicles - Vehicle - specific accidents:

$$
\mathrm{F}_{\text {spec. }}=N_{\text {fines }} / \mathrm{D}_{\text {work } / \text { year }} \cdot N_{\text {vehicle }} \cdot 10^{-6} \text {, }
$$

where $\mathrm{N}_{\text {fines }}$ - a number of offenses detected by the ARS per year; $D_{\text {work/year }}$ - a number of calendar days of the ARS operation in the year under consideration;

$$
\mathrm{RA}_{\text {spec. }}=N_{\text {driver.accid. }} / \mathrm{D}_{\mathrm{y}} \cdot N_{\text {vehicle }} \cdot 10^{-6},
$$

where $\mathrm{N}_{\text {vehicle }}$ - a number of registered vehicles, pcs.; $\mathrm{N}_{\text {driver. accid. }}$ - a number of accidents caused by vehicle drivers per year; Dy - a number of calendar days per year.

Thus, increasing the RNW equipping of the regions with the ARS stations will allow the state to increase traffic safety, and the private partner to profit from the ARS operation and maintenance. As shown in Fig. 4, the effect of the ARS application on RNW in terms of accidents reduction is not instantly provided, but in the period from the year of ARS operation, which provides a payback to a private partner.

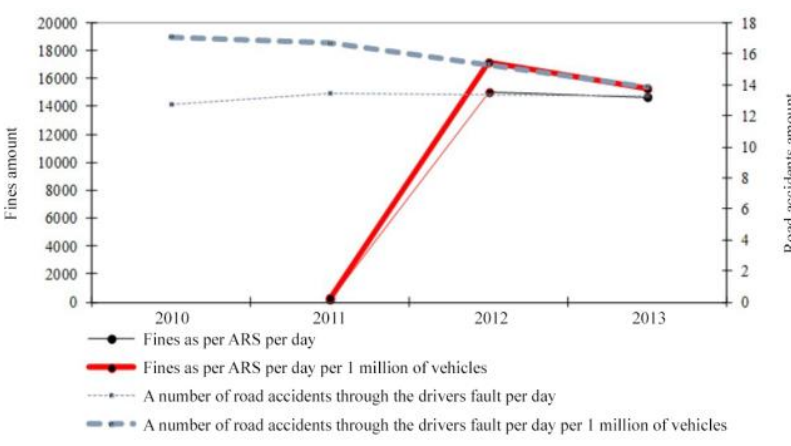

Fig. 4. ARS effect on accident rate.

\section{RESULTS}

The implementation of automatic recording systems in the traffic safety practice is one of the most important measure providing reduction of mortality on roads. However, the accident rate on Russian roads remains high and in this connection it is necessary to look for ways of innovative development of transport infrastructure, which is also reflected in implementing the ARS digital model based on effective mechanisms of interaction between the state and business, which is possible within the framework of PPP. The required mechanism for managing the automatic recording system structure elements to ensuring traffic safety based on PPP shall determine the cooperation of organizations and institutions (objects interconnection) relating to the content, development, improvement and financial support of the entire system.

The methods of partnership participants (elements) interaction based on the PPP mechanism shall increase in the efficiency of implementing the tasks to ensure road traffic safety when applying the ARS digital model.
Therefore, the automatic recording system management pattern developed by organizations and institutions during interaction in the field of traffic control shall include the solutions of many particular tasks, which will ensure effective management of all components of the automatic recording system $[13,14]$.

In order to develop a management pattern based on the PPP interaction mechanism in the field of traffic safety when using ARS, it is necessary to determine a set of functional elements of the system that interact with each other to achieve a common goal of the traffic safety.

The automatic recording system has a material, technical and organizational-structural basis, as well as other functionally necessary structural elements coordinating the activities in the field of traffic safety. The quality and efficiency of using this basis highly depends on the efficiency of practically implemented technologies for the functioning of individual elements of the system as a whole. The quality of managing the system and the respective implemented management decisions shall be considered in accordance with the formulation of the actual tasks for their solution. In this regard, the interaction structure of organizations and institutions providing traffic safety when applying the automatic recording systems shall be as follows (Fig. 5).

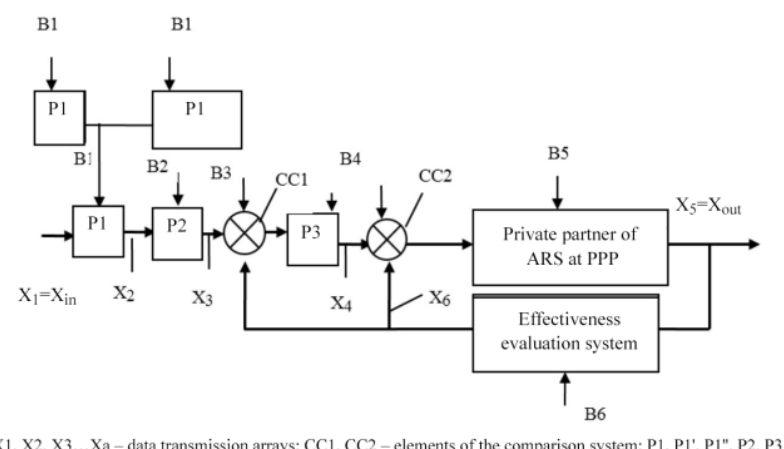

$\mathrm{X} 1, \mathrm{X} 2, \mathrm{X} 3 \ldots \mathrm{Xa}$ - data transmission arrays; $\mathrm{CC} 1, \mathrm{CC} 2$ - elements of the comparison system; $\mathrm{P} 1, \mathrm{Pl}$,
elements of the automatic recording system; $\mathrm{B} 1, \mathrm{~B} 2, \mathrm{~B} 3, \mathrm{~B} 4, \mathrm{~B} 5$ - $\mathrm{ARS}$ elements functioning factors

Fig. 5. The mechanism of elements interaction in the traffic safety system applying the automatic recording systems within the framework of PPP.

As a result of applying the PPP mechanism in the traffic safety system using the ARS digital model, a typical set of managerial functions and feedbacks is implemented, which provides for the control over the execution of tasks and management mechanisms necessary for the system efficiency. The functional management elements and feedbacks in the management channels with commercial organizations presented in the pattern have an extensive set of various nature of properties and characteristics, the level of which is subject to special assessment. These properties include: efficiency, reliability, accuracy, speed, control performance, cost, completeness or volume of data received, etc., which may be the subject of further research in the field of PPP application to implement ARS and digitize the transport infrastructure.

\section{DISCUSSION}

The PPP mechanism application for the ARS implementation to improve the transport infrastructure safety is a form of mutually beneficial cooperation between the state and the private sector, making it possible to 
increase the social and economic efficiency of the digital technologies implementation in the transport sector through using the available financial reserves. From the state side, the main competence is to develop the ARS arrangement pattern to reduce the accident rate of the transport infrastructure and increase the level of safety of its functioning, while a private partner directly invests in the implementation of innovative technologies and receives indirect benefits related to the ARS operation.

According to the statistics, only $58 \%$ of the fines identified with the help of ARS are paid by offenders, therefore it is required to use the reserves of a private partner to increase the fines collection level [11]. Continuous control over the situation at the transport infrastructure facilities allows collecting a significant amount of information, which is expressed in distributing the big-data technology within the framework of the digital transformation of the transport sector. Selling the public information collected and accessible for external services in the field of transport infrastructure will allow a private partner to earn additional profit and recoup the costs.

So, in New York, on the big-data basis, the principles of taxi and car sharing services are being improved by analyzing data on common routes, their congestion, length and accurate geo-location [15]. Moreover, the use of bigdata by state control bodies can be carried out in order to select priority projects for development of transport infrastructure based on analyzing the information about the most emergency sections of the road network [16].

Abroad, the digital technologies are used to optimize transport processes based on the active interaction of private organizations and the state. In Spain, the road sections with an increased accident rate are constantly monitored. This allows detecting that $70 \%$ of traffic accidents are caused by overspeeding [17]. The digital technologies like ARS allow analyzing the drivers' behavior at various sections of roads, since the most modern safety cameras have the ability to calculate an average vehicle speed along the route, which increases the system accuracy and a number of detected offenses.

Thus, digital technologies in the field of automatic offenses recording are the basis not only for traffic offenses detection, but also allow collecting information that is used by commercial organizations to improve the operation of special digital applications, and also facilitates analyzing the traffic situation in time and space in order to reduce accidents at transport infrastructure facilities.

\section{SUMMARY}

The development of transport infrastructure, roads, their transport and operational condition and safety have a significant impact on the economy, the quality of population life, preservation of citizens' life and health. One of the socially important tasks is to ensure traffic safety. System analysis in this subject domain has showed that the issues of managing the roads performance in the field of their maintenance, control and traffic safety with applying the digital model based on the systems for automatic offenses recording are not fully developed.

As a result of road traffic accidents, 1.2 million people die every year in the world, 50 million are injured [4], and it is obvious that solution regarding the issue of transport infrastructure safety cannot be achieved without the use of modern digital technologies. The ARS implementation as a digital model at transport infrastructure facilities is one of the effective measures to improve the road infrastructure; however, it is necessary to develop a mechanism for implementing such projects. In our opinion, the application of the PPP mechanism to improve the transport infrastructure safety is one of the options for projects implementation to introduce the ARS under conditions of budget deficit.

The PPP mechanism application when implementing the digital technologies and, in particular the ARS, allows for effective interaction between the state and the private sector, while achieving the goals of the partnership participants improving the transport infrastructure safety in accordance with the planned state indicators and making profit by a private partner through system maintenance and using the big-data for cooperation with third-party organizations related to the transport sector.

As of 2018, Russia is implementing 87 PPP projects in the field of transport infrastructure with a total rate of private investments in the amount of 1.031 billion rubles [18]. The majority of PPP projects in the transport sector of Russia are associated with the highways construction, modernization of large transport hubs, and the draft system for charging heavy trucks using the federal roads "Platon" [19] is especially noted, however, automatic recording systems are aimed at increasing road safety, which is important in general for the development of transport infrastructure and in matters of reducing mortality in the country, since only these systems are the basis for a digital model of transport infrastructure.

As a result of the study, the measures were developed to increase traffic safety using ARS based on the PPP mechanism. Application of automatic offenses recording systems in Russia based on the public-private partnerships will ensure the implementation of innovative approaches to the development of the digital economy in this subject domain due to the distribution of information and communication technologies that provide the transport infrastructure digitalization.

The pattern of ARS digital model management proposed in the study was developed taking into account the currently existing data processing sequences which makes it possible to apply the developed mechanism in practice without global structural changes, which will allow to adjust the effective interaction of organizations and institutions in the field of traffic safety in Russia. The proposed solutions will allow achieving high economic efficiency by means of using the PPP mechanism being mutually beneficial for business and the state. The active application of automatic recording tools ensures implementing the principle of inevitability of punishment, which provides the agreement private partner with guarantees of payback on its investment in projects aimed at traffic safety applying the automatic recording systems.

\section{REFERENCES}

[1] A. Marusin, A. Marusin and I. Danilov, "A method for assessing the influence of automated traffic enforcement system parameters on traffic safety," Transportation Research Procedia, vol. 36, 2018, pp. 500-506, https://doi.org/10.1016/j.trpro.2018.12.136. 
[2] M. Siemiatycki, "The Theory and Practice of Infrastructure PublicPrivate Partnerships Revisited: The Case of the Transportation Sector," Journal of the American Planning Association, vol. 76, issue 1, 2009, pp. 43-58, https://www.tandfonline.com/doi/abs/10.1080/01944360903329295

[3] A. Vishnivetskaya and E. Alexandrova, “«Smart city» concept. Implementation practice," IOP Conference Series: Materials Science and Engineering, vol. 497, 012019, 2019, DOI: 10.1088/1757899X/497/1/012019.

[4] E.V. Dinges, "Methods of planning and assessing the effectiveness of measures to improve traffic safety": monograph, Moscow: MADI, 2016, p. 140.

[5] A.V. Marusin, "Rational use of means for automatic recording of administrative offenses," Advances in modern science: International Research Magazine, vol. 4(8), 2016, pp. 11-12.

[6] RF Government Decree N 864 dated 03.10.2013 "On the federal target program "Traffic Safety Improvement in 2013-2020"," https://mvd.ru/upload/site1/folder_page/010/469/824/PP_864_from_0 3_10_2013.pdf.

[7] Regulation of the government of the Russian Federation No. 1-p dated January 8, 2018 "Strategy of traffic safety in the Russian Federation for 2018 - 2024", http://www.consultant.ru/cons/cgi/online.cgi?req=doc\&base=LAW\& $\mathrm{n}=288413 \&$ fld $=134 \& \mathrm{dst}=100009,0 \& \mathrm{rnd}=0.7426296895814621 \# 079$ 77616922023352.

[8] RF Government Decree N 100 dated 20.02.2006 "On the federal target program "Traffic Safety Improvement in 2006-2012"," http://base.garant.ru/189189/.

[9] M. Kerimov, R. Safiullin, A. Marusin and A. Marusin, "Evaluation of functional efficiency of automated traffic enforcement systems," Transportation Research Procedia, vol. 20, 2017, pp. 288-294, DOI: https://doi.org/10.1016/j.trpro.2017.01.025.

[10] R. Safiullin, M. Kerimov, A. Afanasyev and A Marusin, "A model for justification of the number of traffic enforcement facilities in the region," Transportation Research Procedia, vol. 36, 2018, pp. 493499, https://doi.org/10.1016/j.trpro.2018.12.135.

[11] A.V. Marusin, "On the question of assessing the effectiveness of applying the means of automatic recording of offenses in order to increase the traffic safety level," Advances in modern science: International Research Magazine, vol. 2(10), 2016, pp. 117-119.

[12] R. N. Safiullin, M. A. Kerimov and A.V. Marusin, "Improving the efficiency of the system for photo and video recording of administrative traffic offenses," Civil Engineers Bulletin, vol. 56 (3), 2016, pp. 233-237.

[13] E. Adell, A. Várhelyi and M.D. Fontana, "The effects of a driver assistance system for safe speed and safe distance - A real-life field study," Transportation Research Part C: Emerging Technologies, vol. 19(1), 2011, pp. 145-155.

[14] P. A. Kravchenko, "On innovative technologies in the field of traffice safety", Transport of the Russian Federation, vol. 30 (5), 2010, pp. 68-71.

[15] P. Santi, G. Resta and C. Ratti, "Quantifying the Benefits of Taxi Trips in New York through Shareability Networks," PNAS, vol. 11(37), 2014, pp. 13290-13294.

[16] OECD, "International Transport Forum. Big Data and Transport: Understanding and assessing options," 2015, https://www.itfoecd.org/sites/default/files/docs/15cpb_bigdata_0.pdf

[17] J. Gonzalez, "Using Telematics Big Data for Road Safety Analysis," 2017, https://www.geotab.com/blog/big-data-for-road-safety/.

[18] S. Luzan, V. Sokolov and V. Meleshkov, "Success factors and key risks in PPP transport projects," PwC, 2018, http://p3transport.ru/doc/presentations/masterklass_gchp_v_transportnoi_infrastrukture_19092018.pdf.

[19] T.Kh. Ablyazov and A.V. Marusin, "Public Private Partnership as a Mechanism for Transport Infrastructure Development in the Digital Economy Formation," Economic Relations, vol. 9(2), 2019, DOI: 10.18334/eo.9.2.40593 